\title{
FGF23 and Malnutrition in Maintenance Hemodialysis Patients: A Single-Center Study
}

\author{
Aref $\mathbf{H}^{1}$, Ezzat $\mathbf{H}^{1^{*}}$ and Elsayed $\mathbf{W}^{2}$ \\ ${ }^{1}$ Department of Internal Medicine, Nephrology Division, Ain Shams University, Egypt \\ ${ }^{2}$ Department of Clinical Pathology, Ain Shams University, Egypt
}

"Corresponding author: Haitham Ezzat, Faculty of Medicine, Department of Internal Medicine, Nephrology Division, Ain Shams University, Cairo, Egypt, Tel: +201006499550; E-mail: haitham_ezzat@hotmail.com

Received date: November 28, 2016; Accepted date: December 20, 2016; Published date: December 29, 2016

Copyright: $\odot 2017$ Aref et al. This is an open-access article distributed under the terms of the Creative Commons Attribution License, which permits unrestricted use, distribution, and reproduction in any medium, provided the original author and source are credited.

\begin{abstract}
Background: Malnutrition is a prevalent complication in patients on maintenance hemodialysis and is considered a major risk factor for mortality in those patients. FGF23 has also been associated with mortality in dialysis patients. Little is known about the association between FGF23 and malnutrition in such patients.
\end{abstract}

Aim of the study: The aim of this study was to investigate possible relationship between FGF23 and malnutrition in maintenance hemodialysis patients. 85 patients on maintenance hemodialysis were studied. In addition to routine laboratory parameters, serum intact fibroblast growth factor-23 levels were done, and anthropometric measures were done after reaching dry weight which included MAC, WC and WHR. BMI was calculated for all patients. SGADMS (Subjective Global Assessment -Dialysis Malnutrition Score) was calculated based on medical history and clinical examination.

Results: The mean BMI was $20.2 \pm 3 \mathrm{~kg} / \mathrm{m}^{2}$. The mean hemoglobin level was $9.7 \pm 2 \mathrm{~g} / \mathrm{dl}$. The mean serum calcium level was $7.6 \pm 1 \mathrm{mg} / \mathrm{dl}$. The mean serum albumin was $3.9 \pm 1 \mathrm{~g} / \mathrm{dl}$. The mean mid-arm circumference was $22.9 \pm 2 \mathrm{~cm}$. The mean waist circumference was $90.5 \pm 11 \mathrm{~cm}$. The mean malnutrition score was $28.2 \pm 3$ points. FGF23 levels ranged from 13.5 to $675 \mathrm{ng} / \mathrm{L}$, and accordingly patients were divided into four quartiles. Patients in the lowest FGF23 quartile showed the shortest dialysis vintage, lowest serum calcium, phosphorus, creatinine, albumin, total proteins, MAC, and the highest iPTH level. The highest malnutrition score was associated with the lowest FGF23 quartile. There was highly significant positive correlation between FGF23 level and each of BMI, WHR $(p=0.006$ and 0.001 respectively) and a highly significant negative correlation with malnutrition score $(p=0.000)$.

Conclusion: Low FGF23 levels may be associated with malnutrition in maintenance hemodialysis patients. FGF23 used in conjunction with other objective nutritional assessment tools may be of value in determining nutritional status of hemodialysis patients.

Keywords Fibroblast growth factor-23; Malnutrition; Hemodialysis

Abbreviations BMI: Body Mass Index; FGF23: Fibroblast Growth Factor 23; MAC: Mid Arm Circumference; PTH: Parathyroid Hormone; SGA-DMS: Subjective Global Assessment-Dialysis Malnutrition Score; WC: Waist Circumference; WHR: Waist to Hip Ratio

\section{Introduction}

Bone-derived fibroblast growth factor23 (FGF23) is a phosphaturic hormone that has recently emerged as a key regulator in the body's complex axis of mineral metabolism [1]. Several epidemiological studies have observed the relationship between declining kidney function and rising FGF23 concentrations [2,3]. In addition, increased circulating FGF23 appears to portend adverse outcomes in patients with CKD3, [4-6]. As a harbinger of poor outcomes, FGF23 joins an already robust group of established metabolic risk factors afflicting patients with end-stage renal disease (ESRD). Much of the focus on FGF23 has attempted to establish a link between the hormone and maladaptive changes in phosphate homeostasis. However, recent investigators have attempted to shed light on novel associations between FGF23 and factors unrelated to mineral metabolism [7]. Phylogenic and sequence analyses have shown that FGF23 shares common structural and biological features with FGF19 and FGF21, which are members of the FGF19 subfamily [8]. The FGF19 subfamily has emerged as a set of novel factors that regulate diverse metabolic processes [9]. Importantly, both FGF19 and FGF21 have been implied in the regulation of lipid and glucose metabolism [10-14]. Proteinenergy malnutrition is a common complication of hemodialysis and a major risk factor for mortality in patients on maintenance hemodialysis $[15,16]$. Mild to moderate malnutrition occurs in about one third of maintenance dialysis patients and severe malnutrition occurs in approximately $6 \%$ to $8 \%$ of those patients [17]. The reliable assessment of nutritional status requires multidisciplinary procedures, including anthropometric measurements, body composition measurements, biochemical measurements, functional assessments, dietary assessments, and subjective assessments [17,18]. Subjective global assessment-Dialysis malnutrition score (SGA-DMS) is a fully quantitative reproducible instrument for assessing the nutritional status of dialysis patients $[19,20]$. The aims of the present study were (1) to describe the demographic, clinical, and nutritional 
Page 2 of 6

characteristics in a cohort of ESRD patients who were on maintenance hemodialysis program in our unit, (2) to test, whether FGF23 associates with malnutrition in maintenance hemodialysis patients, and whether it correlates with SGA-DMS and commonly used anthropometric measurements in such patients.

\section{Patients and Methods}

The subjects were recruited from maintenance hemodialysis patients at Ain Shams university hospital in the period from January 2016 to June 2016. The study inclusion criteria were ongoing hemodialysis therapy for 6 months and a stable condition without causes of malnutrition other than CKD as hepatic insuffiency, severe acute heart failure, diabetes mellitus, malignancy, pulmonary diseases, active collagen diseases and patients on steroid therapy. 85 consecutive patients (44 males and 41 females) were enrolled in this study. The mean age was $38.5 \pm 9.4$ years, the median (IQR) for dialysis vintage was 84 (37-177.5) months. Hemodialysis was performed 3 times/week for 4 hours with the use of hollow-fiber dialyzers and a bicarbonate buffered dialysate. Written informed consent was obtained from all participants after informing them about the steps of study and capability to withdraw at any time. The study protocol was approved by the ethics committees of Ain Shams university faculty of medicine. History taking, physical examinations, anthropometric measurements, and blood analyses were performed in the same week for each patient.

\section{All patients were subjected to}

\section{Blood analyses}

Full blood count, serum creatinine, blood urea nitrogen (BUN), serum sodium, potassium, phosphorus, calcium, serum albumin and total serum proteins were measured by standard laboratory techniques with the use of an automatic analyzer. Serum intact parathyroid hormone was performed using Cobas p480 supplied by Roche molecular diagnostics. Serum intact fibroblast growth factor-23 levels (FGF-23) done using human fibroblast growth factor-23 (FGF-23) ELISA kits supplied by Glory Science Co., Ltd (2400 Veterans Blvd. Suite 16 - 101, Del Rio, TX 78840, USA). Nutritional assessment using edema-free body weight, body mass index (BMI), mid-arm circumference (MAC), waist circumference (WC), waist to hip ratio (WHR), and SGA-DMS. Body mass index (BMI): Measured according to the formula of [Weight $(\mathrm{kg}) /$ Height $\left(\mathrm{m}^{2}\right)$ ] in which the weight was measured in (kilogram) using the balanced digital scale for all subject (wearing light clothing). Height was measured (in meter) using a flexible tape with the patient standing without shoes, heals together and the head in the horizontal plane. Mid-arm circumference: Measured with a flexible non stretchable measure tape. The patient was asked to stand with his/her feet together, shoulders relaxed, and arms hanging freely at the sides. The non-access (fistula free) arm was located to avoid the possibility of an inaccurate measurement. The midpoint on the posterior aspect of the upper arm was established between the acromial and olecranon and marked with a pencil. The measuring tape was placed around the upper arm at midpoint and pulled snugly enough to ensure contact with the arm. The measurement was recorded to the nearest centimeter. Normal values of mid upper arm circumference in male $(26-29 \mathrm{~cm})$ and in female $(26-28.5 \mathrm{~cm})$. Waist circumference $(\mathrm{WC})$ and waist to hip ratio (WHR): The (WC) was taken to the nearest $0.5 \mathrm{~cm}$ with a flexible non stretchable tape measure on the horizontal plane at the level midpoint between the lower rib margin and the iliac crest. WC $\geq 102 \mathrm{~cm}$ for men and $\geq 88 \mathrm{~cm}$ for women were regarded as abnormal. The (WHR) measured by the ratio between waist circumference (WC) to hip circumference (HC) which was taken as the maximal circumference around the buttocks posteriorly and pubic symphysis anterior to the level of a greater trochanter, the ratio of (WHR) was considered abnormal if $>1$ in male and $>0.85$ in female. SGA-DMS: is a fully quantitative scoring system consisting of seven features: weight change, dietary intake, gastrointestinal symptoms, functional capacity, comorbidity, subcutaneous fat and signs of muscle wasting. Each component has a score from 1 (normal) to 5 (very severe). Thus the malnutrition score (sum of all seven components) is a number between 7 (normal) to 35 (severely malnourished). A lower score denotes normal nutritional status and a higher score is an indicator of the presence of malnutrition elements, that is the higher the SGA-DMS the stronger the tendency towards protein energy malnutrition [19] as described in Figures 1-3.

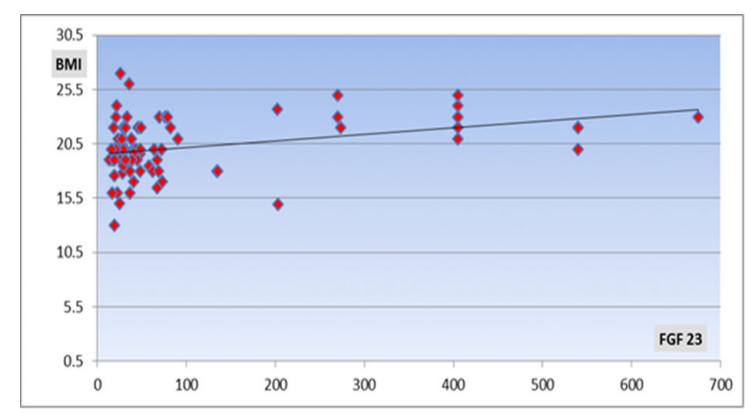

Figure 1: Correlation between BMI and serum FGF-23 levels.

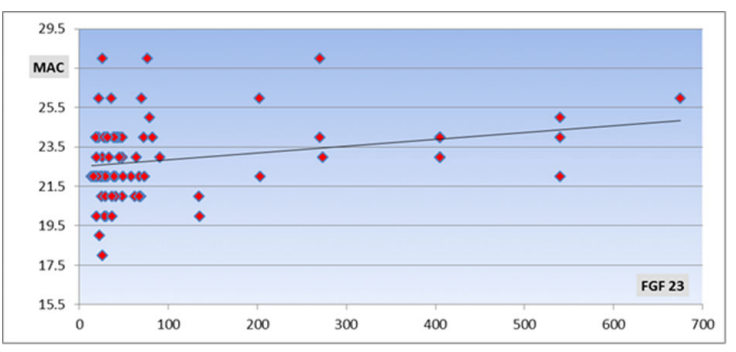

Figure 2: Correlation between MAC and serum FGF23 levels.

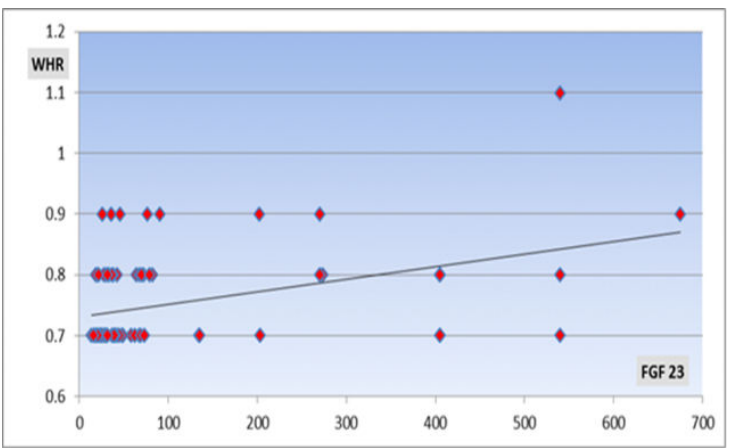

Figure 3: Correlation between WHR and serum FGF23 levels. 
Citation: Aref H, Ezzat H, Elsayed W (2016) FGF23 and Malnutrition in Maintenance Hemodialysis Patients: A Single-Center Study. J Kidney 2:

Page 3 of 6

\section{Statistical Methods}

IBM SPSS statistics V. 22.0 was used for data analysis. Dates were expressed as Mean \pm SD for quantitative parametric measures in addition to Median Percentiles for quantitative non-parametric measures and both number and percentage for categorized data.

\section{Results}

All of the subjects $(n=85)$ were Egyptian, there were 44 males (54.1\%) and 41 females (45.9\%). The mean age was $38.5 \pm 9.4$ years. The mean BMI was $20.2 \pm 3 \mathrm{~kg} / \mathrm{m}^{2}$. The mean hemoglobin level was $9.7 \pm 2 \mathrm{~g} / \mathrm{dl}$. The mean serum calcium level was $7.6 \pm 1 \mathrm{mg} / \mathrm{dl}$. The mean serum albumin was $3.9 \pm 1 \mathrm{~g} / \mathrm{dl}$. The mean mid-arm circumference was $22.9 \pm 2 \mathrm{~cm}$. The mean waist circumference was $90.5 \pm 11 \mathrm{~cm}$. The mean malnutrition score was $28.2 \pm 3$ points. The median (IQR) FGF23 levels was 39 (25.5-74.5) ranging from $13.5 \mathrm{ng} / \mathrm{L}$ to $675 \mathrm{ng} / \mathrm{L}$. The median (IQR) for dialysis vintage was 84 (37-177.5) ranging from 5 to 300 months. The median (IQR) for body weight was 60 (49.5-71) ranging from 32 to $110 \mathrm{~kg}$. The median (IQR) for phosphorus level was 6 (4.8-7.3) ranging from 2.8 to $9.2 \mathrm{mg} / \mathrm{dl}$. The median (IQR) for PTH was 659 (239.5-1049) ranging from 18.4 to $3461 \mathrm{pg} / \mathrm{dl}$. The median (IQR) for serum creatinine level was 6.3 (4.9-7.8) ranging from 2.1 to $12.9 \mathrm{mg} / \mathrm{dl}$. The median (IQR) for waist to hip ratio was $0.7(0.7-0.8)$ ranging from 0.7 to $8 \%$. FGF23 levels had a wide range value, so for accurate statistical analysis, it was divided into four quartiles.

Tables [1] and [2] show descriptive and comparative analysis of the four FGF23 quartiles for parametric and non-parametric data respectively for all the included patients.

\begin{tabular}{|c|c|c|c|c|c|c|}
\hline $\mathbf{P}$ & $\mathbf{F}$ & Q4 (n=21) & Q3 (n=21) & Q2 (n=21) & $\begin{array}{l}\text { Q1 } \\
(n=22)\end{array}$ & FGF-23 \\
\hline & & (73.5-657) & $(39.5-73)$ & $(25.5-39)$ & $(13.5-25)$ & (ng/L) \\
\hline 0.241 & 1.43 & $36.9 \pm 9$ & $36.7 \pm 10$ & $38.4 \pm 9$ & $41.9 \pm 9$ & Age (years) \\
\hline 0.527 & 0.75 & $132 \pm 39$ & $139 \pm 31$ & $125 \pm 29$ & $137 \pm 30$ & $\mathrm{SBP}(\mathrm{mmHg})$ \\
\hline 0.399 & 0.99 & $82.9 \pm 22$ & $88 \pm 19$ & $78.5 \pm 18$ & 85.215 & $\mathrm{DBP}(\mathrm{mmHg})$ \\
\hline 0.155 & 1.79 & $163.5 \pm 18$ & $171.4 \pm 13$ & $173.4 \pm 13$ & $172 \pm 16$ & $\mathrm{Ht}(\mathrm{cm})$ \\
\hline $0.004^{* *}$ & 4.71 & $21.8 \pm 2$ & $20 \pm 3$ & $19.6 \pm 2$ & $19.3 \pm 2$ & BMI $\left(\mathrm{kg} / \mathrm{m}^{2}\right)$ \\
\hline 0.071 & 2.43 & $10 \pm 1$ & $10.1 \pm 2$ & $9 \pm 2$ & $9.4 \pm 1$ & $\mathrm{Hb}(\mathrm{g} / \mathrm{dl})$ \\
\hline 0.773 & 0.37 & $189 \pm 25$ & $187.6 \pm 33$ & $197.4 \pm 35$ & $189 \pm 38$ & PIt $\left(10^{3} / \mathrm{dl}\right)$ \\
\hline 0.642 & 0.56 & $4.9 \pm 0.7$ & $4.8 \pm 0.8$ & $4.6 \pm 1$ & $4.8 \pm 1$ & WBCs $\left(10^{3} / \mathrm{dl}\right)$ \\
\hline 0.728 & 0.44 & $7.6 \pm 0.9$ & $7.6 \pm 1$ & $7.7 \pm 1$ & $7.4 \pm 1$ & $\mathrm{Ca}(\mathrm{mg} / \mathrm{dl})$ \\
\hline 0.578 & 0.66 & $4 \pm 0.4$ & $4 \pm 0.4$ & $3.9 \pm 0.6$ & $3.8 \pm 0.5$ & Albumin (g/dl) \\
\hline 0.058 & 0.6 & $135 \pm 8$ & $141.2 \pm 10$ & $141.5 \pm 8$ & $139 \pm 8$ & $\mathrm{Na}(\mathrm{mmol} / \mathrm{L})$ \\
\hline 0.22 & 3.39 & $4 \pm 0.7$ & $4.7 \pm 0.8$ & $4.6 \pm 0.8$ & $4.4 \pm 0.5$ & $\mathrm{~K}(\mathrm{mmol} / \mathrm{L})$ \\
\hline 0.217 & 1.51 & $6.9 \pm 1$ & $7.5 \pm 2$ & $7 \pm 0.9$ & $6.7 \pm 0.8$ & Total Proteins (g/dl) \\
\hline 0.203 & 1.57 & $193 \pm 35$ & $205 \pm 41$ & $195 \pm 44$ & $177 \pm 50$ & Urea-pre(mg/dl) \\
\hline 0.67 & 0.52 & $61.7 \pm 13$ & $63 \pm 13$ & $67.1 \pm 19$ & $64 \pm 14$ & Urea-post (mg/dl) \\
\hline $0.025^{*}$ & 3.3 & $23.9 \pm 2$ & $22.8 \pm 1$ & $22.2 \pm 2$ & $22.2 \pm 2$ & $\operatorname{MAC}(\mathrm{cm})$ \\
\hline 0.609 & 0.61 & $92.9 \pm 13$ & $89.8 \pm 9$ & $88.4 \pm 11$ & $91 \pm 12$ & WC $(\mathrm{cm})$ \\
\hline $0.0001^{* *}$ & 24.9 & $24.8 \pm 4$ & $29 \pm 1$ & $29 \pm 2$ & $29.8 \pm 2$ & Malnutri-Score (points) \\
\hline
\end{tabular}

Table 1: Descriptive \& comparative analysis of the four FGF23 quartiles in parametric parameters in all hemodialysis patients. Data are shown as mean values with standard deviation (Mean $\pm \mathrm{SD}$ ) for parametric data. $\mathrm{F}$ analysis of variance (ANOVA) for parametric data. $\mathrm{P}>0.05$ : Non significant difference ${ }^{*} \mathrm{P}<0.05$ : Significant difference ${ }^{* *} \mathrm{P}<0.01$ : Highly significant difference.

Patients in the lowest FGF23 quartile showed the shortest dialysis vintage, lowest serum calcium, phosphorus, creatinine, albumin, total proteins, MAC and the highest PTH level. The highest malnutrition score was associated with the lowest FGF23 quartile, whereas the lowest score was associated with the highest FGF23 quartile. Ranke Spearman Correlation test showed a highly significant positive correlation between FGF23 level and each of BMI, WHR, and a highly significant negative correlation with malnutrition score, also there were a significant positive correlation with each of age and MAC, and a significant negative correlation with $\mathrm{Kt} / \mathrm{V}$. There was a non-significant negative correlation with each of $\mathrm{Ca}, \mathrm{PTH}, \mathrm{Na}, \mathrm{K}$, and serum creatinine and a non -significant positive correlation with WC (Table 
Citation: Aref H, Ezzat H, Elsayed W (2016) FGF23 and Malnutrition in Maintenance Hemodialysis Patients: A Single-Center Study. J Kidney 2:

Page 4 of 6

3). Multi-regression analysis showed that FGF23 was independently associated with age $(\mathrm{p}=0.04)$, weight $(\mathrm{p}=0.001)$, height $(\mathrm{p}=0.003)$, MAC ( $\mathrm{p}=0.01)$, and malnutrition score $(\mathrm{p}=0.001)$ (Table 4$)$.

\section{Discussion}

Malnutrition is highly prevalent in hemodialysis (HD) patients, and it contributes to morbidity and mortality. Fibroblast growth factor-23 (FGF23) and Klotho contribute to chronic kidney disease-mineral and bone disorder (CKD-MBD) in HD patients, but the role that these molecules play in determining nutritional status is currently unknown [21]. The primary finding of this study is that patients in the lowest FGF23 quartile had the lowest serum calcium, phosphorus, creatinine, albumin, total proteins, BMI, and the highest malnutrition score, which reflected their worse nutritional status compared with the other quartiles. This partially agrees with the results of Mizuiri et al. who reported that among all their studied maintenance hemodialysis patients, the lowest BMI, normalized protein equivalent of nitrogen appearance (nPNA) [22], normalized protein catabolic rate (nPCR) [23], geriatric nutritional risk index (GNRI) [24], serum albumin, creatinine, phosphate, $\mathrm{Ca}, \mathrm{Ca} \times \mathrm{P}$ product and $\mathrm{iPTH}$ values were seen in the lowest serum FGF-23 quartile (FGF-23<311 pg/ml) [25]. The mean body mass index of our studied population was $20.2 \pm 3 \mathrm{~kg} / \mathrm{m}^{2}$. In fact, HD patients exhibit lower BMIs than age and sex-matched control subjects from the general population [26]. Based on this observation, previous study has shown that increased BMI contributes to survival advantages in dialysis patients [27].

\begin{tabular}{|l|l|l|l|l|l|l|}
\hline $\mathbf{P}$ & $\mathbf{H}$ & $\mathbf{Q} \mathbf{4} \mathbf{n} \mathbf{2 1}$ & $\mathbf{Q 3} \mathbf{( n = 2 1 )}$ & $\mathbf{Q} \mathbf{2}(\mathbf{n}=\mathbf{2 1})$ & $\mathbf{Q} \mathbf{~ ( n = 2 2 )}$ & FGF-23 (ngL) \\
\hline & & $\mathbf{7 3 . 5 - 6 7 5}$ & $\mathbf{3 9 . 5 - 7 3}$ & $\mathbf{2 6 - 3 9}$ & $\mathbf{1 3 . 5 - 2 5 . 5}$ & \\
\hline 0.47 & 2.53 & $168(36-222)$ & $90(37-198)$ & $84(36-150)$ & $84(58-147)$ & Duration (months) \\
\hline 0.21 & 4.53 & $1.54(1.2-1.7)$ & $1.3(1.1-1.4)$ & $1.1(0.9-1.5)$ & $1.2(1-1.5)$ & KT/N \\
\hline 0.76 & 1.17 & $56(44.5-74)$ & $55.5(50-68.5)$ & $63(54.5-70.5)$ & $61(48-73.2)$ & Wt (kg) \\
\hline 0.756 & 1.19 & $6.7(4.7-7.6)$ & $6.5(4.9-7.55)$ & $6.2(5-7.3)$ & $5.7(4.2-6.9)$ & PO4 (mg/dl) \\
\hline 0.289 & 3.75 & $427(179-1037)$ & $643.5(195-1229)$ & $389(231-1040)$ & $744(582-1342)$ & PTH (pg/dL) \\
\hline 0.128 & 5.69 & $5.7(4.2-7.2)$ & $7.6(5.4-8.9)$ & $6.9(5.2-7.5)$ & $5.4(4.9-8.4)$ & S-Cr (mg/dl) \\
\hline $0.001^{* *}$ & 15.4 & $0.8(0.7-0.9)$ & $0.7(0.7-0.8)$ & $0.7(0.7-0.8)$ & $0.7(0.7-0.7)$ & WHR (cm) \\
\hline
\end{tabular}

Table 2: Descriptive \& comparative analysis of the four FGF-23 quartiles in non-parametric parameters in all hemodialysis patients. Data are shown as median values with 25 and $75 \%$ interquartile ranges Median (IQR) for non-parametric data. $\mathrm{H}$ (Kruskall Wallis Test) for nonparametric data. $\mathrm{P}>0.05$ : Non significant differences ${ }^{*} \mathrm{P}<0.05$ : Significant differences ${ }^{* *} \mathrm{P}<0.01$ : Highly significant differences.

\begin{tabular}{|c|c|c|c|}
\hline Significance & $\mathbf{p}$ & $r$ & Parameter \\
\hline s & $0.034^{*}$ & 0.23 & Age (years) \\
\hline NS & 0.133 & 0.164 & Duration (month) \\
\hline s & $0.017^{*}$ & -0.258 & $\mathrm{Kt} / \mathrm{V}$ \\
\hline NS & 0.803 & 0.027 & $\mathrm{SBP}(\mathrm{mmHg})$ \\
\hline NS & 0.543 & 0.067 & $\mathrm{DBP}(\mathrm{mmHg})$ \\
\hline NS & 0.626 & -0.054 & Wt (kg) \\
\hline NS & 0.096 & -0.182 & $\mathrm{Ht}(\mathrm{cm})$ \\
\hline HS & $0.006^{* *}$ & 0.295 & BMI $\left(\mathrm{kg} / \mathrm{m}^{2}\right)$ \\
\hline NS & 0.064 & 0.202 & $\mathrm{Hb}(\mathrm{g} / \mathrm{dl})$ \\
\hline NS & 0.895 & -0.015 & PIt (10/dl) \\
\hline NS & 0.617 & 0.055 & WBCs $\left(10^{3} / \mathrm{dl}\right)$ \\
\hline NS & 0.295 & -0.115 & $\mathrm{Ca}(\mathrm{mg} / \mathrm{dl})$ \\
\hline NS & 0.55 & 0.066 & PO4 (mg/dl) \\
\hline NS & 0.07 & -0.197 & PTH (pg/dl) \\
\hline NS & 0.54 & 0.067 & Alb (g/dl) \\
\hline
\end{tabular}


Page 5 of 6

\begin{tabular}{|l|l|l|l|}
\hline NS & 0.279 & -0.119 & Na (mmol/L) \\
\hline NS & 0.441 & -0.085 & K (mmol/L) \\
\hline NS & 0.457 & 0.082 & TP (g/dl) \\
\hline NS & 0.683 & -0.045 & S_createnine (mg/dl) \\
\hline S & $0.012^{*}$ & 0.27 & MAC (cm) \\
\hline NS & 0.406 & 0.091 & WC (cm) \\
\hline HS & $0.001^{* *}$ & 0.369 & WHR (\%) \\
\hline HS & $0 *$ & -0.587 & Malnut_Score (points) \\
\hline
\end{tabular}

Table 3: Correlation between FGF-23 levels values in $\mathrm{ng} / \mathrm{L}$ and all studied parameters in all hemodialysis patients. Ranked Sperman Correlation Test: FGF23. $\mathrm{P}>0.05$ : Non significant correlation. ${ }^{*} \mathrm{P}<0.05$ : Significant correlation. ${ }^{* *} \mathrm{P}<0.01$ : Highly significant correlation.

\begin{tabular}{|l|l|l|l|l|l|l|l|}
\hline Parameter & $\begin{array}{l}\text { Regression } \\
\text { Coefficient }\end{array}$ & t-value & p-value & Significance & F-Ratio & p & Significance \\
\hline (constant) & -0.498 & -0.166 & 0.869 & NS & & \\
\hline Age & -0.022 & -2.091 & 0.04 & S & & \\
\hline Duration & 0.002 & 1.679 & 0.097 & NS & & & \\
\hline Weight & -0.064 & -3.514 & 0.001 & HS & 12.813 & 0 & HS \\
\hline Height & 0.05 & 3.071 & 0.003 & HS & & \\
\hline MAC & 0.198 & 2.653 & 0.01 & S & & & \\
\hline Malnut_Score & -0.275 & -6.569 & 0.0001 & HS & & \\
\hline
\end{tabular}

Table 4: Multi-Regression analysis of FGF23 as a dependent variable and the studied parameter that had a significant relation with it. P>0.05: Non significant difference. ${ }^{*} \mathrm{P}<0.05$ : Significant difference. ${ }^{*} \mathrm{P}<0.01$ : Highly significant difference.

The obesity paradox [28-31] has created much debate in the renal community regarding the protective effect of obesity in ESRD patients. A recent systematic review [32] of the relationship between BMI and mortality supported the inverse association between BMI and all-cause mortality in adult HD patients, especially in elderly patients. Given that uremic lipid patterns and lower BMI have been linked with increased mortality in patients with advanced kidney disease requiring chronic dialysis $[26,33,34]$ exploration of a potential interrelationship between FGF23 and these risk factors remains an attractive field for research. In a nested case-control sample of 400 patients in the Accelerated Mortality on Renal Replacement (ArMMOR) study, high FGF23 levels were shown to predict 1 year mortality independent of phosphate levels 4. FGF23 levels were also associated with higher mortality in patients with near normal levels of phosphate. A prospective cohort study of 219 dialysis patients undergoing 5-8 h dialysis also demonstrated an association between FGF23 levels and mortality, again independent of phosphate 35 . It has been suggested that increased circulating FGF23 levels are independently associated with mortality in incident and prevalent hemodialysis patients $[4,35]$. However, the median follow-up time in the latter studies was 12 months and 24 months, respectively. Conversely, other studies did not detect any association between circulating FGF23 levels and mortality in hemodialysis patients [36,37]. According to the report by Gutiérrez et al., a combination of increased circulating FGF23 levels and normal or low serum phosphate levels is a significant risk factor for mortality
$(\mathrm{P}<0.02$; odds ratio: 1.8$)$, whereas a combination of high circulating FGF23 levels and high serum phosphate levels $(>5.5 \mathrm{mg} / \mathrm{dl})$ is not $(\mathrm{P}=0.29$; odds ratio: 1.1) 4. Another significant finding in this study is the significant positive correlation between FGF23 and nutritional parameters notably BMI, MAC, WHR and malnutrition score, and the significant negative correlation with $\mathrm{Kt} / \mathrm{V}$ which to our knowledge has not been shown in any studies before. Our study has some limitations. First, due to the cross-sectional study design, a longitudinal causal relationship could not be established between the changes in the plasma FGF23 levels and alterations in malnutrition score and other anthropometric measures. Second, the generalizability of our results is not clear because of the relatively small number of patients in our single-centre study. Larger sample sizes and validation among different cohorts are needed to confirm these results.

\section{References}

1. Shimada T, Hasegawa H, Yamazaki Y, Muto T, Hino R, et al. (2004) FGF-23 is a potent regulator of vitamin D metabolism and phosphate homeostasis. J Bone Miner Res 19: 429-435.

2. Larsson T, Nisbeth U, Ljunggren O, Juppner H, Jonsson KB (2003) Circulating concentration of FGF-23 increases as renal function declines in patients with chronic kidney disease, but does not change in response to variation in phosphate intake in healthy volunteers. Kidney Int 64: 2272-2279. 
3. Gutierrez OM, Januzzi JL, Isakova T, Laliberte K, Smith K, et al. (2009) Fibroblast growth factor 23 and left ventricular hypertrophy in chronic kidney disease. Circulation 119: 2545-2552.

4. Gutierrez OM, Mannstadt M, Isakova T, Hain JAR, Tamez H, et al. (2008) Fibroblast growth factor 23 and mortality among patients undergoing hemodialysis. N Engl J Med 359: 584-592.

5. Isakova T, Xie H, Yang W, Xie D, Anderson AH, et al. (2011) Fibroblast growth factor 23 and risks of mortality and end-stage renal disease in patients with chronic kidney disease. JAMA 305: 2432-2439.

6. Kendrick J, Cheung AK, Kaufman JS, Greene T, Roberts WL, et al. (2011) FGF-23 associates with death, cardiovascular events, and initiation of chronic dialysis. J Am Soc Nephrol 22: 1913-1922.

7. Mirza MA, Alsio J, Hammarstedt A, Erben RG, Michaëlsson K, et al (2011) Circulating fibroblast growth factor-23 is associated with fat mass and dyslipidemia in two independent cohorts of belderly individuals. Arterioscler Thromb Vasc Biol 31: 219-227.

8. Itoh N, Ornitz DM (2008) Functional evolutionary history of the mouse Fgf gene family. Dev Dyn 237: 18-27.

9. Itoh N, Ornitz DM (2004) Evolution of the Fgf and Fgfr gene families Trends Genet 20: 563-569.

10. Tomlinson E, Fu L, John L, Hultgren B, Huang X, et al. (2002) Transgenic mice expressing human fibroblast growth factor-19 display increased metabolic rate and decreased adiposity. Endocrinology 143: 1741-1747.

11. Fu L, John LM, Adams SH, Yu XX, Tomlinson E, et al. (2004) Fibroblast growth factor 19 increases metabolic rate and reverses dietary and leptindeficient diabetes. Endocrinol 145: 2594-2603.

12. Kharitonenkov A, Shiyanova TL, Koester A, Ford AM, Micanovic R, et al. (2005) FGF-21 as a novel metabolic regulator. J Clin Invest 115: 1627-1635.

13. Coskun T, Bina HA, Schneider MA, Dunbar JD, Hu CC, et al. (2008) Fibroblast growth factor 21 corrects obesity in mice. Endocrinology 149: 6018-6027.

14. Xu J, Lloyd DJ, Hale C, Stanislaus S, Chen M, et al. (2009) Fibroblast growth factor 21 reverses hepatic steatosis, increases energy expenditure and improves insulin sensitivity in diet-induced obese mice. Diabetes 58 250-259.

15. Harvey KB, Blumenkrantz MJ, Levine SE, Blackburn GL (1980 Nutritional assessment and treatment of chronic renal failure. Am J Clin Nutr 33: 1586-1597.

16. Kopple JD (1994) Effect of nutrition on morbidity and mortality in maintenance dialysis patients. Am J Kidney Dis 24: 1002-1009.

17. Jones JM (2002) The methodology of nutritional screening and assessment tools. J Hum Nutr Diet 15: 59-71.

18. Kondrup J, Allison SP, Elia M, Vellas B, Plauth M (2003) ESPEN guidelines for nutrition screening 2002. Clin Nutr. 22: 415-421.

19. Kalantar-Zadeh K, Kleiner M, Dunne E, Lee GH, Luft FC (1999) A modified quantitative subjective global assessment of nutrition for dialysis patients. Nephrol Dial Transplant 14: 1732-1738.

20. Kalantar-Zadeh K, Kopple JD, Block G, Humphreys MH (2001) A malnutrition-inflammation score is correlated with morbidity and mortality in maintenance hemodialysis patients. Am J Kidney Dis Dec 38: 1251-1263.

21. Fukasawa H, Ishigaki S, Kinoshita-Katahashi N, Niwa H, Yasuda H, et al. (2014) Plasma levels of fibroblast growth factor-23 are associated with muscle mass in haemodialysis patients. Nephrology (Carlton) 19: 784-790.

22. Kopple JD (2000) Clinical practice guidelines for nutrition in chronic renal failure. K/DOQI, National Kidney Foundation. Am J Kidney Dis 37: S1-140.

23. Shinzato T, Nakai S, Fujita Y, Takai I, Morita H, et al. (1994) Determination of $\mathrm{Kt} / \mathrm{V}$ and protein catabolic rate using pre- and postdialysis blood urea nitrogen concentrations. Nephron 67: 280-290.

24. Yamada K, Furuya R, Takita T, Maruyama Y, Yamaguchi Y, et al. (2008) Simplified nutritional screening tools for patients on maintenance hemodialysis. Am J Clin Nutr 87: 106-113.

25. Mizuiri S, Nishizawa Y, Yamashita K, Ono K, Oda M, et al. (2014) Lower serum fibroblast growth factor-23 levels may suggest malnutrition in maintenance haemodialysis patients. Nephrology (Carlton) 19: 568-573.

26. Kopple JD, Zhu X, Lew NL, Lowrie EG (1999) Body weight-for-height relationships predict mortality in maintenance hemodialysis patients. Kidney Int 56: 1136-1148.

27. Cabezas-Rodriguez I, Carrero JJ, Zoccali C, Qureshi AR, Ketteler M, et al. Influence of body mass index on the association of weight changes with mortality in hemodialysis patients. Clin J Am Soc Nephrol 8: 1725-1733.

28. Kalantar-Zadeh K, Abbott KC, Salahudeen AK, Kilpatrick RD, Horwich TB (2005) Survival advantages of obesity in dialysis patients. Am J Clin Nutr Mar 81: 543-554.

29. Schmidt DS, Salahudeen AK (2007) Obesity-survival paradox-still a controversy? Semin Dial 20: 486-492.

30. Stolic R (2010) Obesity in renal failure--health or disease? Med Hypotheses 75: 497-500.

31. Grzegorzewska AE (2009) The role of nutritional status in the outcome of peritoneal dialysis patients. Panminerva Med 51: 163-173.

32. Herselman M, Esau N, Kruger JM, Labadarios D, Moosa MR (2010) Relationship between body mass index and mortality in adults on maintenance hemodialysis: a systematic review. J Ren Nutr 20: 281-292.

33. Kwan BC, Kronenberg F, Beddhu S, Cheung AK (2007) Lipoprotein metabolism and lipid management in chronic kidney disease. J Am Soc Nephrol 18: 1246-1261.

34. Leavey SF, McCullough K, Hecking E, Goodkin D, Port FK, et al. (2001) Body mass index and mortality in 'healthier' as compared with 'sicker' haemodialysis patients: results from the dialysis outcomes and practice patterns study (DOPPS). Nephrol Dial Transplant 16: 2386-2394.

35. Jean G, Terrat JC, Vanel T, Hurot JM, Lorriaux C, et al. (2009) High levels of serum fibroblast growth factor (FGF)-23 are associated with increased mortality in long haemodialysis patients. Nephrol Dial Transplant 24: 2792-2796.

36. Hsu HJ, Wu MS (2009) Fibroblast growth factor 23: a possible cause of left ventricular hypertrophy in hemodialysis patients. Am J Med Sci 337: 116-122.

37. Olauson H, Qureshi AR, Miyamoto T, Barany P, Heimburger O, et al. (2010) Relation between serum fibroblast growth factor-23 level and mortality in incident dialysis patients: are gender and cardiovascular disease confounding the relationship? Nephrol Dial Transplant 25: 3033-3038. 